\title{
CARACTERÍSTICAS DE ALGUMAS SOLUÇÕES TAMPÃO UTILIZADAS PARA AVALIAR A ACIDEZ DO SOLO *
}

\author{
R. A. CAtani ** \\ A. O. JACINTHO ** \\ A. Pizzinatto $* * *$
}

\section{RESUMO}

\begin{abstract}
Estudou-se o comportamento das soluções tampão SMP, Woodruff original, Woodruff $(1+1),(1+2)$ e $(1+3)$, acetato de cálcio $1,00 \mathrm{~N}-$ $0,50 \mathrm{~N}$ e $0,25 \mathrm{~N}$, frente a quantidades variáveis de ácidos clorídrico, acético, cítrico e salicílico.

Foram calculados os valores da capacidade ou índice tampão de todas as soluções $\mathrm{e}$ as equações de regressão relativas às variações do $\mathrm{pH}$ das soluções em função da quantidade de ácido clorídrico adicionada. No caso da solução SMP, foram estabelecidas, também, as equações de regressão para os ácidos acético, cítrico e salicílico.
\end{abstract}

\section{INTRODUÇÃO}

$\mathrm{O} \mathrm{pH}$ do solo, que indica a atividade do íon hidroxônio $\left(\mathrm{H}_{3} \mathrm{O}^{+}\right.$, na suspensão aquosa do solo, é uma resultante da ação ou interação dos vários componentes denominados componentes da acidez do solo. Os citados componentes podem ser resumidos em: a) íons hidroxônios $\mathrm{H}_{3} \mathrm{O}^{+}$, adsorvidos às partículas coloidais; b) íons monômeros de alumínio $\left|\mathrm{Al}\left(\mathrm{H}_{2} \mathrm{O}\right)_{6}\right|^{3+}$ e/ou $\left.\mid \mathrm{AlH}_{2} \mathrm{O}\right)\left._{5}(\mathrm{OH})\right|^{2+}$ e/ou $\left|\mathrm{Al}\left(\mathrm{H}_{2} \mathrm{O}\right)_{4}(\mathrm{OH})_{2}\right|+$ também adsorvidos às partículas coloidais; c) íons polímeros de alumínio $\left[\mathrm{Al}_{\mathrm{m}}\left(\mathrm{H}_{2} \mathrm{O}\right)_{\mathrm{n}}(\mathrm{OH})_{\mathrm{p}}\right](3 \mathrm{~m}-\mathrm{p})+$ associados a diversos componentes do solo; d) os hidrogênios dos carboxilos $\mathrm{e}$ dos grupos fenóis também denominados por hidrogênio covalente (COLEMAN' \& THOMAS, 1967; CATANI \& ALONSO, 1969a e 1969b).

Apesar dos íons hidroxônio e monômero de alumínio adsorvidos se evidenciarem como os componentes mais ativos da acidez de di-

\footnotetext{
* Entregue para publicação em 19/12/1972.

** Departamento de Química da E.S.A. "Luiz de Queiroz".
}

*** Bolsista da FAPESP. 
versos solos, a influência dos outros componentes, íons polímeros de alumínio e carboxilos, pode também apresentar importância em vários solos (CATANI \& ALONSO, 1969a). Resulta daí o interesse em se determinar os vários componentes da acidez, quando se tem em vista a elevação do $\mathrm{pH}$ do solo, isto é, a correção da acidez pela adição de neutralizantes.

A determinação dos vários componentes da acidez do solo pode ser conduzida por diversos métodos e técnicas (COLEMAN \& THOMAS, 1967; FREITAS \& OUTROS, 1968; CATANI \& ALONSO, 1969b), dentre os quais figuram as soluções tampão.

Um solução tampão quando colocada em contato com um determinado peso de certa amostra de solo, extrai prótons dos diversos componentes da acidez e, como consequiência, o pH da solução decresce de acordo com certas características do solo e da solução tampão. Dentre as características de solução tampão, destacam-se a capacidade tampão e o tipo de variação, linear ou não linear, do pH em função da quantidade de prótons adicionada ou recebida.

O objetivo do presente trabalho é o de estudar a capacidade tampão e a variação do $\mathrm{pH}$ de algumas soluções tampão, que apresentam interesse na avaliação da acidez do solo, através da adição de quantidades conhecidas de ácidos clorídrico, acético, cítrico e salicílico.

\section{MATERIAL E MÉTODOS}

\section{Soluções tampão}

As soluções tampão estudadas foram as seguintes:

1 - Solução de WOODRUFF (1948) - Dissolver $40 \mathrm{~g}$ de acetato de cálcio monohidratado em $650-700 \mathrm{ml}$ de água destilada e transferir para balão volumétrico de 1 litro. Dissolver $8 \mathrm{~g}$ de 4-nitrofenol em 200-220 ml de água a $80-90^{\circ} \mathrm{C}$ e transferir para o balão de 1 litro que contém o acetato. Esfriar a solução, ajustar o pH a 7,0, com soluções de $\mathrm{NaOH}$ a 40 e $20 \%$.

2 - Solução de WOODRUFF $(1+1(1+2)$ e $(1+3)$ - Diluir a solução . $^{\circ} 1$ na proporção de $1: 1,1: 2$ e $1: 3$, respectivamente, com água destilada. (1961).

3 - Solução SMP ou de SHOEMAKER, McLEAN \& PRATT

a) Dissolver, sucessivamente, $3,0 \mathrm{~g}$ de cromato de potássio, 2,0 $\mathrm{g}$ de acetato de cálcio monohidratado e $4,0 \mathrm{~g}$ de cloreto de cálcio dihi- 
dratado em $800 \mathrm{ml}$ de água destilada; transferir para balão volumétrico de 1 litro, adicionar $2,5 \mathrm{ml}$ de trietanolamina e homogeneizar. $80-90^{\circ} \mathrm{C}$.

b) Dissolver 1,8 $\mathrm{g}$ de 4-nitrofenol em $100-120 \mathrm{ml}$ de água a

Adicionar a solução $\mathbf{b}$, ainda quente, à solução $\mathbf{a}$, homogeneizar, esfriar e acertar o pH para 7,40 ou 7,50 com solução de $\mathrm{NaOH}$ a $20 \%$ ou do $\mathrm{HCl}(1+1)$, completar o volume e agitar. Na presente preparação foi necessária a utilização de solução de $\mathrm{HCl}(1+1)$ para acertar o pH a 7,40-7,50.

4 - Solução de acetato de cálcio 1,00 N (CATANI \& ALONSO, 1969b) - Dissolver 88,1 g de acetato de cálcio monohidratado em $850-900 \mathrm{ml}$ de água destilada em copo de 1 litro; acertar o $\mathrm{pH}$ para 7,0 através de solução de ácido acético glacial $(1+1)$ ou de amônia $(1+1)$; transferir para balão volumétrico de 1 litro, completar o volume e homogeneizar. Nesta preparação, empregou-se solução de ácido acético glacial (1+1) para ajustar o $\mathrm{pH}$ a 7,0.

5 - Soluções de acetato de cálcio 0,50 e $0,25 \mathrm{~N}$ - Diluir a solução $1,00 \mathrm{~N}$ de acetato de cálcio, na proporção de $(1+1)$ e $(1+3)$, respectivamente, com água destilada.

\section{Soluções de ácidos}

As soluções de ácidos utilizadas para provocar decréscimo do $\mathrm{pH}$ das soluções tampão foram:

1 - Solução de $\mathrm{HCl} 1,00 \mathrm{~N}$ - Preparar a partir de $\mathrm{HCl}$ concentrado e padronizar mediante o emprego de carbonato de sódio, como padrão primário.

2 - Soluções de $\mathrm{HCl} 0,10-0,15-0,20-0,25-0,30-0,35$ $-0,40-0,45$ e $0,50 \mathrm{~N}$ - Preparar por diluição da solução de $\mathrm{HCl}$ $1,00 \mathrm{~N}$.

3 - Solução de ácido acético 1,00 N - Preparar a partir da diluição de ácido acético glacial e verificação e acerto após titulação, com solução de $\mathrm{NaOH} 0,250$ a $0,500 \mathrm{~N}$ padronizada.

4 - Soluções de ácido acético $0,10-0,15-0,20-0,25-0,30$ - 0,35-0,40 - 0,45 e $0,50 \mathrm{~N}$ - Preparar por diluição da solução de ácido acético $1,00 \mathrm{~N}$.

5 - Solução de ácido cítrico $1,00 \mathrm{~N}$ - Transferir 70,050 g de ácido cítrico monohidratado $\left(\mathrm{C}_{6} \mathrm{H}_{8} \mathrm{O}_{7} \cdot \mathrm{H}_{2} \mathrm{O}\right)$ para balão volumétrico de 1 litro, dissolver, completar o volume com água destilada e homogeneizar.

6 - Soluções de ácido cítrico $0,10-0,15-0,20-0,25-0,30$ 
$-0,35-0,40-0,45$ e $0,505 \mathrm{~N}$ - Preparar por diluição da solução $1,00 \mathrm{~N}$.

7 - Solução de ácido salicílico ou ácido 2-hidroxibenzóico $\left(\mathrm{OHC}_{6} \mathrm{H}_{4} \mathrm{COOH}\right) 1,00 \mathrm{~N}$ - Transferir 34,530 g de material para copo de $400 \mathrm{ml}$, contendo $180-200 \mathrm{ml}$ de álcool etílico, esperar dissolver, passar para balão volumétrico de $250 \mathrm{ml}$, completar o volume com álcool etílico e homogeneizar.

8 - Soluções de ácido salicílico $0,10-0,15-0,20-0,25-$ $0,30-0,35-0,40-0,45$ e $0,50 \mathrm{~N}-$ Preparar por diluição da solução $1,00 \mathrm{~N}$.

\section{Procedimento :}

a) Transferir, para copos de $50 \mathrm{ml}, 1 \mathrm{ml}$ de solução de ácido ( $\mathrm{HCl} 0,10-0,15-0,20-0,25-0,30-0,35-0,40-0,45$ e $0,50 \mathrm{~N}$; ácido acético, ácido cítrico e ácido salicílico, com as mesmas normalidades descritas para o ácido clorídrico), $4 \mathrm{ml}$ de água destilada e homogeneizar.

b) Adicionar $10 \mathrm{ml}$ de solução tampão (WOODRUFF original; WOODRUFF $(1+1),(1+2)$ e $(1+3)$; acetato de cálcio $1,00 \mathrm{~N}$; acetato de cálcio 0,50 e $0,25 \mathrm{~N}$ ) e homogeneizar.

c) Conduzir uma prova em branco para cada solução "tampão" constituída de $5 \mathrm{ml}$ de água destilada e $10 \mathrm{ml}$ da respectiva solução tampão e homogeneizar.

d) Deixar em repouso durante 20 minutos e determinar o $\mathrm{pH}$ em potenciômetro provido de escala que acuse 0,05 unidade, após a calibração do aparelho com soluções de pH 7,00 e 4,00.

\section{RESULTADOS OBTIDOS E DISCUSSÃO}

Os resultados obtidos constam dos quadros ns. ${ }^{\circ} 1,2,3$ e 4 . Na primeira coluna dos citados quadros, aparece a concentração do ácido (clorídrico ou acético ou cítrico ou salicílico) adicionado na proporção de $1 \mathrm{ml}$ para $10 \mathrm{ml}$ da solução tampão (Woodruff original, Woodruff $(1+1,(1+2)$ e $(1+3)$, SMP, acetato de cálcio $1 \mathrm{~N}, 0,50 \mathrm{e}$ $0,25 \mathrm{~N}$ ) e $4 \mathrm{ml}$ de água destilada, isto é, $1 \mathrm{ml}$ de solução de ácido para um total de $15 \mathrm{ml}$ de solução. Da 2. ${ }^{a}$ a $9 .^{a}$ colunas são apresentados os valores do $\mathrm{pH}$ determinado.

Um exame geral dos dados dos quadros ns. 1 a 4 evidencia que a solução SMP apresentou uma amplitude da variação do $\mathrm{pH}$ maior do que as demais soluções tampão, quando tratadas pelos vários ácidos. Tanto as soluções diluídas de WOODRUFF $(1+1),(1+2)$ e $(1+3)$ como as de acetato de cálcio 0,50 e $0,25 \mathrm{~N}$, não apresentaram varia- 


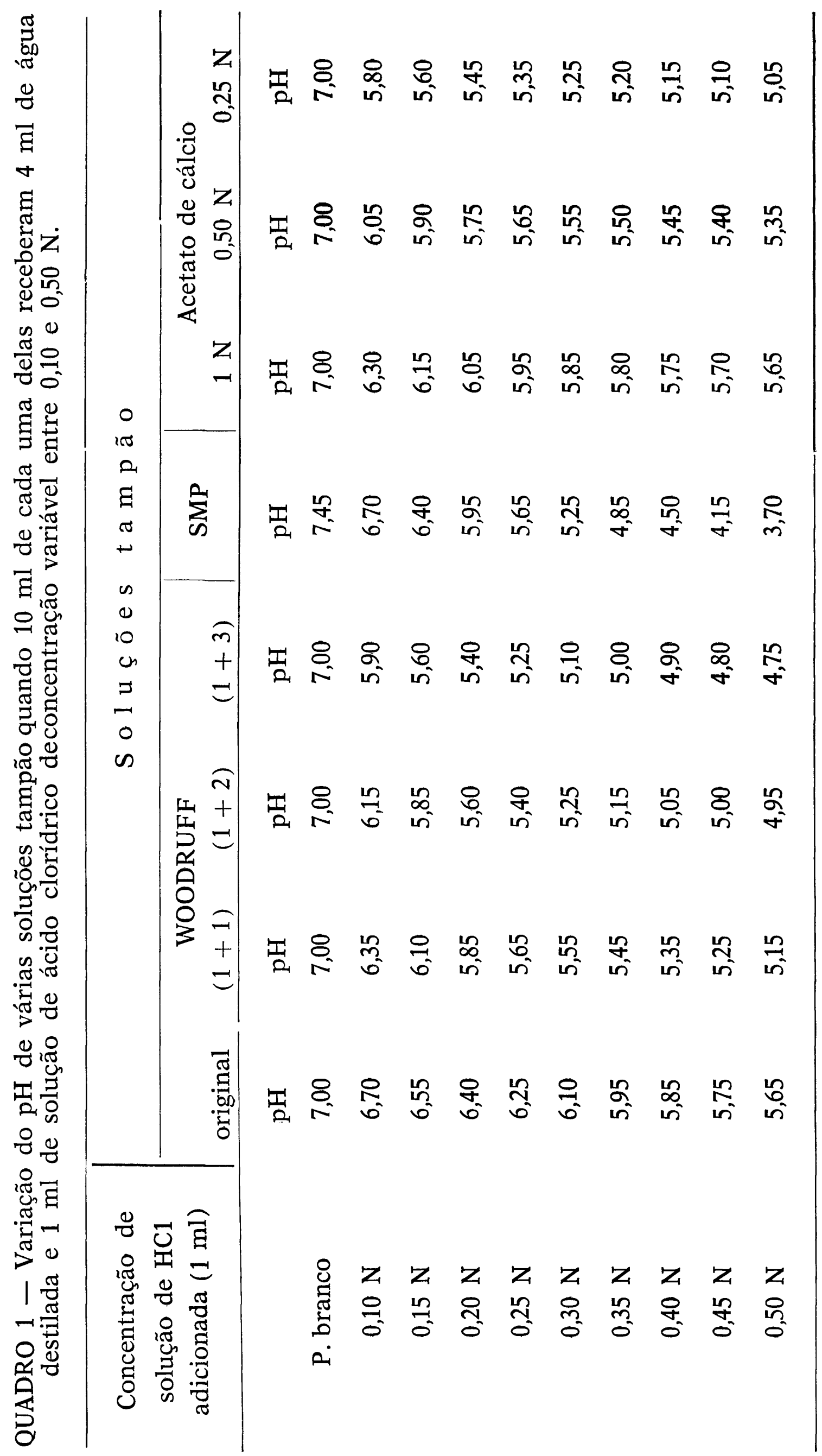




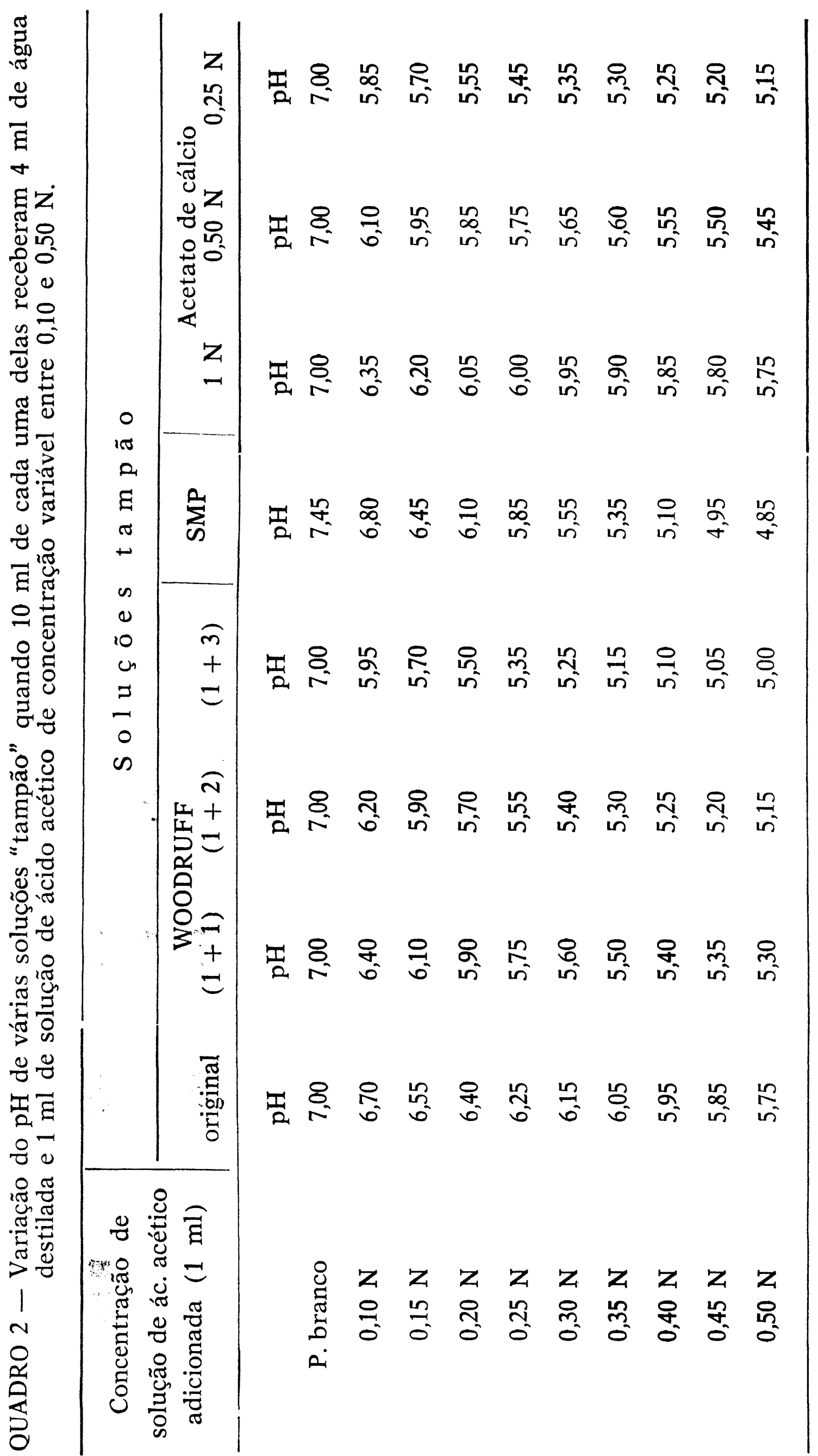




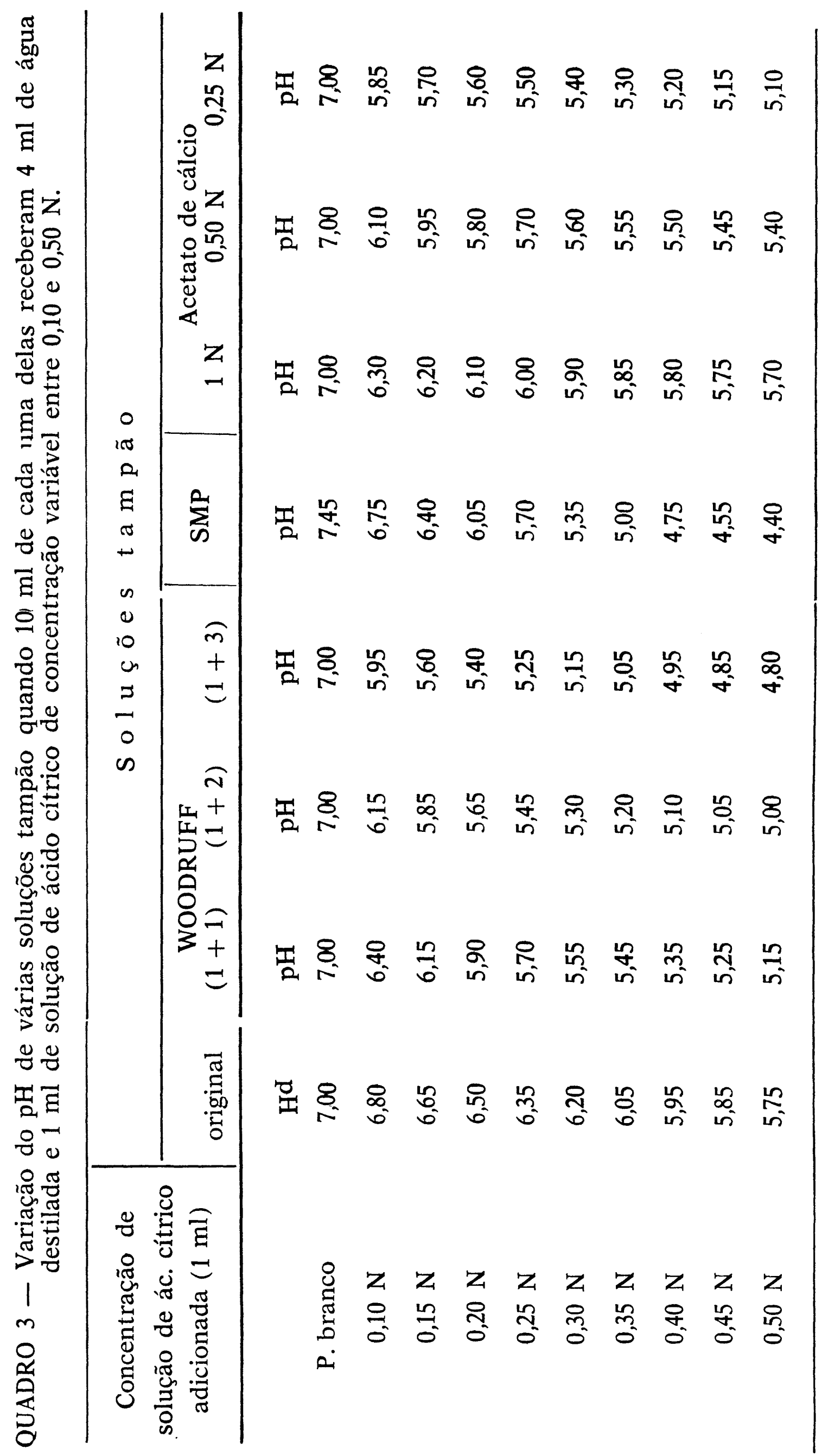




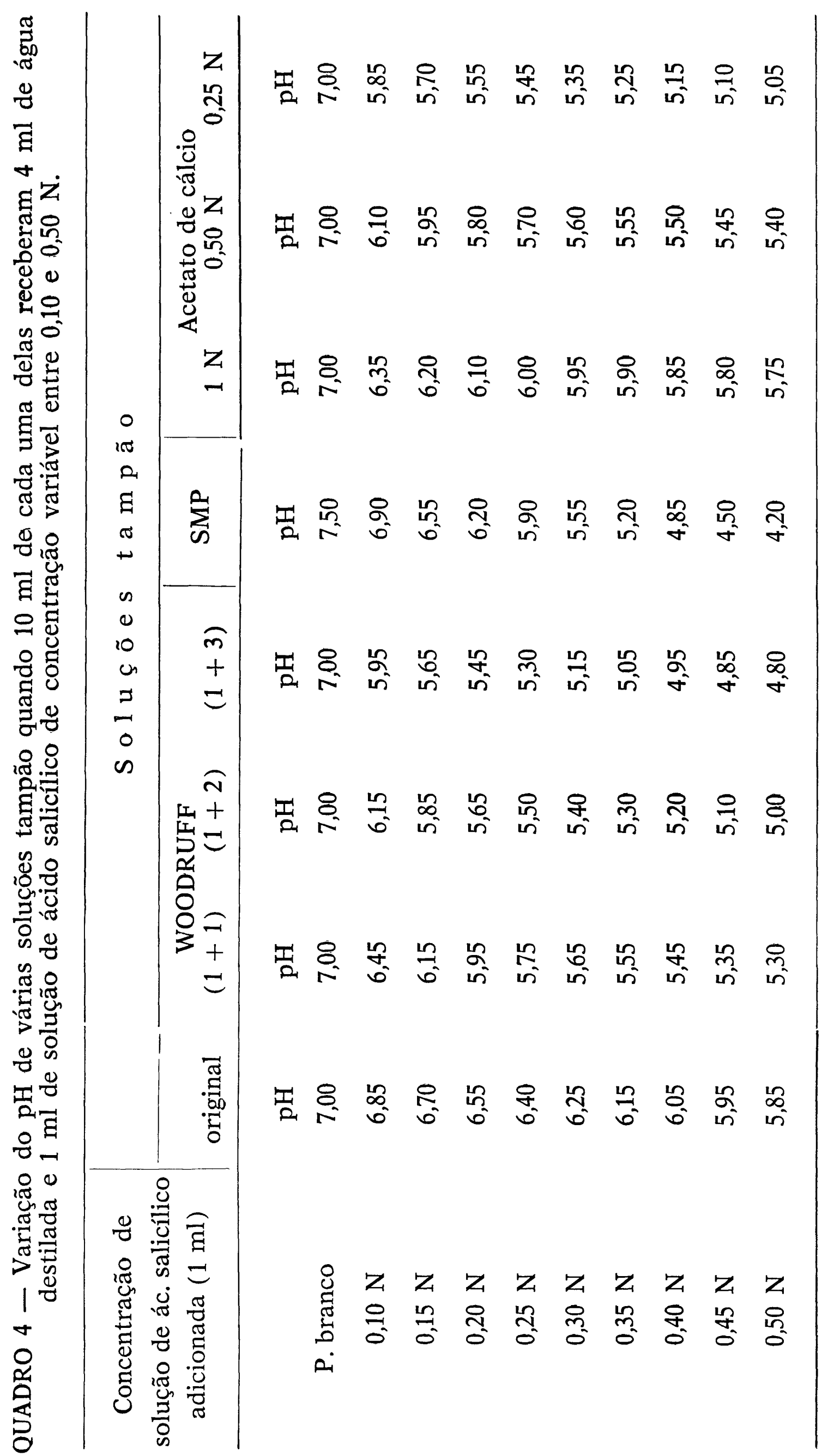


ção em seu pH de mesma magnitude da solução SMP, quando submetidas ao tratamento com os diversos ácidos. Em outras palavras, a capacidade ou índice tampão (BUTLER, 1964 ; DAY \& UNDERWOOD, 1967), da solução SMP é menor do que a das demais soluções estudadas. Calculando-se a capacidade tampão* $(\mathrm{Ct})$ para as soluções SMP, Woodruff original, Woodruff $(1+1)$ e $(1+2)$ em função das quantidades $0,10-0,20-0,30-0,40$ e 0,50 e.mg ou milimol de $\mathrm{HCl}$ adicionado ou contido de $15 \mathrm{ml}$ de solução e as respectivas variações de $\mathrm{pH}$ obtidas, os dados conseguidos constam do quadro 5 .

Os dados do quadro 5 esclarecem que a capacidade tampão da solução SMP revelou-se constante quando se adicionou de 0,0 a 0,50 e. $\mathrm{mg} \mathrm{HCl}$ por $15 \mathrm{ml}$ de solução, apesar de apresentar um valor igual a metade do obtido com a solução de Woodruff original. A solução de Woodruff original mostrou também um comportamento relativamente uniforme, isto é, o valor da capacidade ou índice tampão variou apenas quando se adicionou 0,40 e 0,50 e.mg de $\mathrm{HC} 1$ por $15 \mathrm{ml}$. As demais soluções (Woodruff $(1+1),(1+2)$ e $(1+3)$ e as de acetato de cálcio) mostraram-se variáveis em sua capacidade tampão quando havia variação na quantidade de $\mathrm{HCl}$ adicionada.

QUADRO 5 - Capacidade tampão $\left(\mathrm{C}_{\mathrm{t}}\right.$ ) calculada em função das quantidades $0,10-0,20-0,30-0,40$ e 0,50 e. $\mathrm{mg}$ ou milimol de HC1, contido em $15 \mathrm{ml} \mathrm{de}$ várias soluções tampão e das respectivas variações de $\mathrm{pH}$.

\begin{tabular}{|c|c|c|c|c|c|}
\hline \multirow{2}{*}{ Soluções tampão } & \multicolumn{5}{|c|}{ Adição de $\mathrm{HCl}$ em e.mg/15 ml de solução } \\
\hline & 0,10 & 0,20 & 0,30 & 0,40 & 0,50 \\
\hline & $\mathrm{C}_{\mathrm{t}}$ & $\mathrm{C}_{t}$ & $\mathrm{C}_{\mathrm{t}}$ & $\mathrm{C}_{\mathrm{t}}$ & $\mathrm{C}_{\mathrm{t}}$ \\
\hline SMP & 0,0089 & 0,0089 & 0,0091 & 0,0090 & 0,0089 \\
\hline $\begin{array}{l}\text { Woodruff } \\
\text { original }\end{array}$ & 0,0222 & 0,0221 & 0,0222 & 0,0232 & 0,0247 \\
\hline $\begin{array}{l}\text { Woodruff } \\
(1+1)\end{array}$ & 0,0103 & 0,0116 & 0,0138 & 0,0167 & 0,0180 \\
\hline $\begin{array}{l}\text { Woodruff } \\
(1+2)\end{array}$ & 0,0078 & 0,0095 & 0,0114 & 0,0137 & 0,0163 \\
\hline
\end{tabular}

* A capacidade tampão de uma solução pode ser definida pelo número de equivalentes-gramas de uma base ou de um ácido forte que deve ser adicionado a 1 litro de uma solução para provocar uma variação de uma unidade do $\mathrm{pH}$, isto é, $\mathrm{C}_{\mathrm{t}}=\frac{\mathrm{db}}{\mathrm{dpH}}$ ou $-\frac{\mathrm{da}}{\mathrm{dpH}}$ para a adiçāo de base e de ácido, respectivamente. 
O comportamento da solução SMP pode ser apreciado de um modo mais adequado, quando se coloca no eixo das abcissas o número de equivalentes-miligramas de $\mathrm{HCl}$ adicionado a $15 \mathrm{ml}$ de solução final ( $10 \mathrm{ml}$ de solução tampão SMP e $4 \mathrm{ml}$ de água destilada) e no eixo das ordenadas o valor do $\mathrm{pH}$ obtido, conforme mostra a figura 1 .

A figura 1 mostra uma relação linear entre o $\mathrm{pH}$ e o número de equivalentes-miligramas de $\mathrm{HCl}$ adicionado à solução tampão SMP, cuja equação de regressão é representada pela expressão 1, ondeX é o número de equivalentes-miligramas de $\mathrm{HCl}$ adicionado.

$$
\mathrm{pH}=-\underset{(\mathbf{r} \text { significativo ao nível de } 0,001)}{7,46 \mathrm{X}+7,47}
$$

É evidente que da equação 1 pode-se estabelecer a 2 , isto é, o valor do número de equivalentes-miligramas de $\mathrm{HCl}$ ou de $\mathrm{H}^{+}$em função do $\mathrm{pH}$ da solução.

$$
\mathrm{X}=-0,134 \mathrm{pH}+1,00
$$

A solução SMP mostrou também uma variação linear em seu $\mathrm{pH}$, quando tratada com quantidades crescentes dos ácidos acético, cítrico e salicílico. A partir dos dados dos quadros 1, 2, 3 e 4, foram calculadas as equações de regressão 3, 4 e 5, para os ácidos acético, cítrico e salicílico, respectivamente.

Ácido acético:

$\mathrm{pH}=-4,93 \mathrm{X}+7,15$

Ácido cítrico :

( $\mathbf{r}$ significativo ao nível de 0,001 )

$$
\mathrm{pH}=-\underset{(\mathbf{r} \text { significativo ao nível de } 0,001)}{6,09 \mathrm{X}+7,27}
$$

Ácido salicílico :

$$
\mathrm{pH}=-\underset{(\mathbf{r} \text { significativo ao nível de } 0,001)}{6,78 \mathrm{X}+7,57}
$$

A solução original de Woodruff (WOODRUFF, 1948), assim como as soluções de Woodruff diluídas $(1+1)$ e $(1+2)$ mostraram também uma variação linear em seu $\mathrm{pH}$, quando tratadas com quantidades crescentes de ácido clorídrico. A partir dos dados do quadro 1 foram calculadias as equações de regressão 6,7 e 8 .

Woodruff original :

$$
\mathrm{pH}=-\underset{(\mathbf{r} \text { significativo ao nível de } 0,001)}{2,66 \mathrm{X}}
$$




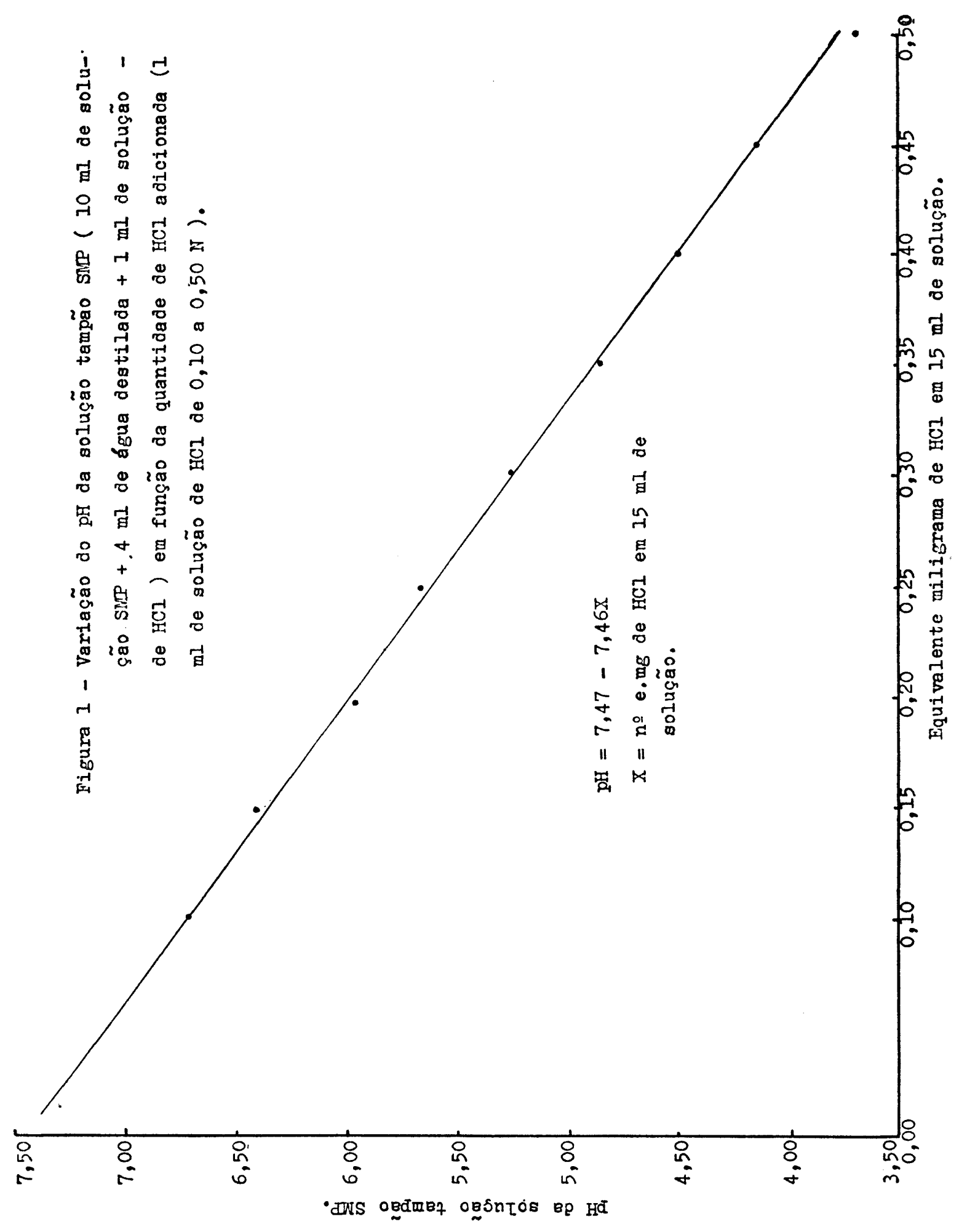


Woodruff $(1+1) \quad$ :

$$
\mathrm{pH}=-2,85 \mathrm{X}+6,49
$$

( $\mathbf{r}$ significativo ao nível de 0,001 )

Woodruff $(1+2)$ :

$$
\mathrm{pH}=-\underset{\text { ( } \mathbf{r} \text { significativo ao nível de } 0,001)}{2,90 \mathrm{X}+6,25}
$$

Finalmente, as soluções de acetato de cálcio $1,00 \mathrm{~N}, 0,50 \mathrm{~N}$ e $0,25 \mathrm{~N}$, com pH 7,0, mostraram também uma variação linear em seu $\mathrm{pH}$, quando tratadas com quantidades crescentes de ácido clorídirico. A partir dos dados do quadro 1, foram calculadas as equações de regressão 9, 10 e 11 .

Acetato de cálcio $1,00 \mathrm{~N}$ :

$$
\mathrm{pH}=-\underset{\text { ( } \mathbf{r} \text { significativo ao nível de } 0,001)}{1,57 \mathrm{X}+6,38}
$$

Acetato de cálcio $0,50 \mathrm{~N}$ :

$$
\mathrm{pH}=-\underset{\text { (r significativo ao nível de } 0,001)}{1,68 \mathrm{X}+6,13}
$$

Acetato de cálcio $0,25 \mathrm{~N}$ :

$$
\mathrm{pH}=-\underset{\text { (r significativo ao nível de } 0,001)}{1,75 \mathrm{X}+5,85}
$$

\section{CONCLUSÕES}

a) A solução tampão SMP ( SHOEMAKER, McLEAN \& PRATT, 1961) cujo $\mathrm{pH}$ inicial era 7,45 , passou para 6,70 e 5,70 , isto é, uma variação de 3,74 unidades, quando $10 \mathrm{ml}$ da mesma recebeu $1 \mathrm{ml}$ de solução de $\mathrm{HCl} 0,10$ e $0,50 \mathrm{~N}$, respectivamente, acrescidos de $4 \mathrm{ml}$ de água destilada.

b) Todas as demais soluções tampão estudadas (WOODRUFF original; WOODRUFF diluída $(1+1)(1+2)$ e $(1+3)$; acetato de cálcio $1,00 \mathrm{~N}, 0,50 \mathrm{~N}$ e $0,25 \mathrm{~N}$ ) apresentaram uma variação bem menor em seu $\mathrm{pH}$, quando submetidas aos mesmos tratamentos.

c) Enquanto a capacidade ou índice tampão da solução SMP apresentou um valor constante, quando foram utilizados $0,10-0,15$ $-0,20-0,25-0,30-0,35-0,40-0,45$ e 0,50 e.mg de $\mathrm{HCl}$ em $15 \mathrm{ml}$ de solução (10 ml de solução tampão, $1 \mathrm{ml}$ de solução de $\mathrm{HCl}$ de 0,10 a $0,50 \mathrm{~N} \mathrm{e} 4 \mathrm{ml}$ de $\mathrm{HCl}$ de água destilada), as demais soluções tampão apresentaram valores variáveis para a citada característica, com exceção da solução WOODRUFF original cuja capacidade tampão variou apenas a partir de 0,40 e. $\mathrm{mg} \mathrm{de} \mathrm{HCl} / 15 \mathrm{ml}$. 
d) As soluções SMP, Woodruff original, Woodruff $(1+1)$ e $(1+2)$; acetado de cálcio 1,00-0,50 e 0,25 $\mathrm{N}$ mostraram uma varialinear em seu $\mathrm{pH}$, quando tratadas com quantidades crescentes de ácido clorídrico e, em todos os casos, o valor do coeficiente de regressão $\mathbf{r}$ foi significativo ao nível de 0,001 .

\section{SUMMARY}

\section{BUFFER CAPACITY OF SOLUTIONS FOR ESTIMATING SOIL ACIDITY}

Buffer capacity or index was determined for SMP, - Woodruff, Woodruff $(1+1),(1+2)$ and $(1+3), 1,00 \mathrm{~N}, 0,50 \mathrm{~N}$ and $0,25 \mathrm{~N}$ calcium acetate solutions. The data obtained showed that SMP solution presented a constant value for buffer capacity when $0.10-0.15-$ $0.20-0.25-0.30-0.35-0.40-0.45$ and 0.50 milliequivalents of $\mathrm{HC1}$ pointing out that the $\mathrm{pH}$ of all solutions decreased linearly water.

The equations were calculated by the method or least squares for the relationship between buffer solution $\mathrm{pH}$ and added amount of $\mathrm{HCl}$ pointing out that the $\mathrm{pH}$ of all solutions decrease linearly with respect to the quantity of $\mathrm{HCl}$ added.

\section{LITERATURA CITADA}

BUTLER, J. N., 1964 - Solubility and $\mathrm{pH}$ Calculatinos. Addison-Wesley Publishing Company, Inc. Reading Massachusetts, USA, $104 \mathrm{pp}$.

CATANI, R. A. \& O. ALONSO, 1969a - Extração do alumínio trocável e o pH do solo. Anais da E.S.A. "Luiz de Queiroz", 26: 21-29.

CATANI, R. A. \& O. ALONSO, 1969b - Avaliação da exigência de calcário do solo. Anais da E.S.A. "Luiz de Queiroz", 26: 141-156.

COLEMAN, N. T. \& G. W. THOMAS, 1967 - The Basic Chemistry of Soil Acidity. Em: Soil Acidity and Liming. Editado por R. W. Pearson \& F. Adams. American Soc. of Agronomy Inc. - Publishers. Madison. Wisconsin. USA. pp. 1-41.

DAY, JR., R. A. \& A. L. UNDERWOOD, 1967 - Quantitative Analysis. Prentice-Hall, Inc. Englewood Cliffs. New Jersey, USA, 482 pp.

FREITAS, L. M. M., P. F. PRATT \& L. VETTORI, 1968 - Testes rápidos para estimar as necessidades em calcário de alguns solos de São Paulo. Pesq. agrop. bras., 3: 159-164.

SHOEMAKER, H. E., E. O. MCLEAN \& P. F. PRATT, 1961 - Buffer methods for determining lime requirements of soils with appreciable amounts of extractable aluminum. Soil Sci. Soc. Amer. Proc., 25: 274-277.

WOODRUFF, C. M., 1948 - Testing soils for lime requirements by means of a buffered solution and the glass electrode. Soil Sci., 66: 53-63. 
